\title{
A New SiC-Whisker-Reinforced Lithium Aluminosilicate Composite
}

\author{
Liang A. Xue* and I-Wei Chen ${ }^{\star}$
}

Department of Materials Science and Engineering, University of Michigan, Ann Arbor, Michigan 48109-2136

\begin{abstract}
The glass-ceramic matrix of the well-known lithium aluminosilicate (LAS)/SiC composite is usually formulated near the spodumene composition. We report here a new composition which is rich in alumina (78 wt\%) and lean in silica $(21 \mathrm{wt} \%)$ and lithia (1 wt \%). This formulation offers a new option of converting the glass-ceramic matrix to a mullite/alumina matrix upon annealing above $1400^{\circ} \mathrm{C}$, and hence better creep resistance and other high-temperature mechanical properties. Using a transient-phase processing method that we developed previously for the superplastic forming of mullite, we are able to hot-press a composite containing 30 vol\% $\mathrm{SiC}$ whiskers at $\sim 1350^{\circ} \mathrm{C}$ to achieve full density. Flexural strength measurements up to $1400^{\circ} \mathrm{C}$ have confirmed the improved high-temperature strength and creep resistance over conventional LAS. The fracture toughness is also higher than that of LAS. The results suggest that the new composition may be chosen as a better candidate matrix for SiC-fiber-reinforced composites.
\end{abstract}

\section{Introduction}

QiliCON CARBIDE fibers, monofilaments, and whiskers have been commonly used in the reinforcement of glasses and glass-ceramics. ${ }^{1-5}$ This produces strong, tough, and refractory ceramic composites. Lithium aluminosilicate (LAS) based glass-ceramics are widely used as the matrix material. These LAS matrices, generally formulated near the spodumene composition, have good processability and a low thermal expansion coefficient which is compatible with $\mathrm{SiC}$ fibers. Although current generation of this family of composites suffers loss of strength due to fiber degradation above $1000^{\circ} \mathrm{C}$, an inherent limitation of these LAS composites is also placed by the softening temperature of the matrix which is also around $1000^{\circ} \mathrm{C}$.

The search for an alternative improved matrix material among more refractory oxides and glass-ceramics encounters inherent difficulty. On one hand, since silicon carbide fibers will probably suffer from chemical and phase stability problems when heated above $1450^{\circ} \mathrm{C},{ }^{6.7}$ none of the crystalline refractory oxides can be used in view of their poor processability below this temperature. On the other hand, if glass-ceramics remain as the choice of the matrix materials, they will always have insufficient strength at higher temperatures.

Recently, we developed a transient-phase processing method to realize large strain shape forming of mullite and mullite/alumina composites ${ }^{8,9}$ In the original process, a superplastic (i.e., one with very good processability) pre-mullite composition is first formed at $1320^{\circ} \mathrm{C}$ by sintering alumina and silica with the addition of $<1$ wt $\%$ lithia. The densified pre-mullite is then shape-formed at $1350^{\circ} \mathrm{C}$ and subsequently annealed at $>1400^{\circ} \mathrm{C}$ to achieve crystallization to mullite. The same process has been extended to cover alumina-rich compositions. ${ }^{9}$ The mullite/alumina composite thus obtained has a strength

P. F. Becher-contributing editor

\footnotetext{
Manuscript No. 195821. Received April 17, 1992; approved February 23, 1993. Supported by U.S. Department of Energy under Grant No. DE-FG0287ER45302.
}

*Member, American Ceramic Society. $(\sim 200 \mathrm{MPa})$ comparable to that of mullite and much higher than that of LAS at temperatures up to $1300^{\circ} \mathrm{C} .{ }^{9}$

In the present study, we have examined the feasibility of using this transient-phase-processed mullite/alumina as the matrix for SiC-fiber- or whisker-reinforced composite. A composition of $78 \mathrm{wt} \%$ alumina, $21 \mathrm{wt} \%$ silica, and $1 \mathrm{wt} \%$ lithia (corresponding to 80 vol\% mullite and 20 vol\% alumina) was used. Direct comparison of flexural strength and toughness was made between this composition and a state-of-the-art LAS (LAS-III), with and without 30 vol\% $\mathrm{SiC}$ whisker. The results show that for the $\mathrm{SiC}$-whisker-reinforced composite the new composition has a processability comparable to that of LAS-III. Significantly improved toughness and high-temperature strength over that of LAS-III are demonstrated.

\section{Experimental Procedure}

The starting materials for the new composition (hereafter referred to as MA) were a high-purity alumina powder with an average particle size of $\sim 0.2 \mu \mathrm{m}$ (AKP-50, Sumitomo Chemical America, Inc., New York) and a high-purity amorphous silica with an average particle size of $\sim 0.04 \mu \mathrm{m}$ (Aerosil OX50, Degussa Corp., Ridgefield Park, NJ). The SiC whiskers used (Tateho Chemical Industries, Japan) were primarily cubic $\beta-\mathrm{SiC}$ with an average diameter of $0.4 \mu \mathrm{m}$ and an aspect ratio of $30-40$.

Silica powder was first dispersed with the aid of a surfactant (Darvan $821 \mathrm{~A}$, R. T. Vanderbilt Co. Inc., Norwalk, CT) in ammonia-contained distilled water under ultrasonic agitation. To the dispersed suspension, an aqueous solution of lithium nitrate was added. The amount of additive introduced was equivalent to $1 \mathrm{wt} \%$ of lithia in a base of 80 vol\% mullite with 20 vol\% alumina ( $78 \mathrm{wt} \%$ alumina with $21 \mathrm{wt} \%$ silica). The slurry was dried and calcined at $1050^{\circ} \mathrm{C}$ for $30 \mathrm{~min}$. The doped silica powder was dispersed again and mixed with alumina powder (and $\mathrm{SiC}$ whisker for composites) by attrition-milling, this time, in 2-propanol. The slurry of the alumina/silica mixture was then cast, under an argon pressure of $1 \mathrm{MPa}$, into cakes of 47-mm diameter, which were dried slowly in air and finally in an oven at temperatures up to $150^{\circ} \mathrm{C}$. (The casting time was less than 5 min for a cake of 5-mm thickness.) After isostatic pressing, the cakes were hot-pressed in argon using a graphite die. Those with 30 vol\% $\mathrm{SiC}$ whisker addition were processed at $1375^{\circ} \mathrm{C}$ and at $40 \mathrm{MPa}$ for $1.5 \mathrm{~h}$ and those without at $1325^{\circ} \mathrm{C}$ and at $30 \mathrm{MPa}$ for $0.5 \mathrm{~h}$. The specimens thus obtained reached a relative density of $>99 \%$ as determined from porosity measurements using standard metallographic lineal analysis. Some samples were further subjected to an annealing treatment at $1450^{\circ} \mathrm{C}$ for $0.5 \mathrm{~h}$ in argon to effect crystallization to mullite. The whisker-reinforced composites are referred to as MA30W and MA30WA, which correspond to the as-hot-pressed and annealed samples, respectively.

The preparation of LAS-III matrix composites was more straightforward. The as-received LAS-III powder (Corning Glass Works, Coming, NY) had an average particle size of $\sim 10$ $\mu \mathrm{m}$ and a proprietary lithium aluminosilicate composition. The particle size was reduced to $<2 \mu \mathrm{m}$ after attrition-milling (and with $\mathrm{SiC}$ whisker in the case of composites) in 2-propanol. The slurry was then pressure cast and dried as described above. Full 
densification of the samples was achieved by hot-pressing $\left(1260^{\circ} \mathrm{C}, 30 \mathrm{MPa}, 1 \mathrm{~h}\right.$ for 30 -vol\%-whisker-reinforced LAS, and $1200^{\circ} \mathrm{C}, 10 \mathrm{MPa}, 0.25 \mathrm{~h}$ for unreinforced LAS). Some specimens were further annealed at $1150^{\circ} \mathrm{C}$ for $8 \mathrm{~h}$ in argon to achieve crystallization. LAS/SiC composites are referred to as LAS30W and LAS30WA, which correspond to the as-hotpressed and annealed samples, respectively.

$\mathrm{X}$-ray diffraction (XRD) using $\mathrm{Ni}$-filtered $\mathrm{Cu} K \alpha$ radiation was employed to monitor the phase evolution. The microstructures of the samples were characterized by scanning electron microscopy (SEM). For the composites, thermal expansion coefficient $\left(20-1082^{\circ} \mathrm{C}\right)$ measurements were conducted in argon before and after annealing using a dilatometer in a direction perpendicular to the hot-pressing axis. The Vickers indentation technique was used to measure hardness and fracture toughness, ${ }^{10}$ by applying a load of $9.8-29.6 \mathrm{~N}$ for the unreinforced matrix materials, and $29.6-98 \mathrm{~N}$ for the composites. Flexural strength measurements up to $1400^{\circ} \mathrm{C}$ were performed in air in four-point bending with an 8-mm inner span and a 16-mm outer span. The specimens, with dimensions of 1.7 $\mathrm{mm} \times 2.8 \mathrm{~mm} \times 20 \mathrm{~mm}$, have their tensile face perpendicular to the hot-pressing axis.

\section{Results}

\section{(I) Phase Evolution}

The as-received LAS-III powder was in an amorphous state as analyzed by XRD. During hot-pressing, substantial crystallization occurred. This is illustrated in Fig. 1 for whisker-reinforced LAS-III, using XRD patterns of as-hot-pressed and annealed samples. The extent of crystallization of the mainly $\beta$-spodumene phase ${ }^{11}$ and a small amount of other lithium aluminosilicate phases, such as $\mathrm{Li}_{2} \mathrm{Al}_{2} \mathrm{Si}_{3} \mathrm{O}_{10}$, was nearly complete in the as-hot-pressed sample. Further annealing at $1150^{\circ} \mathrm{C}$ for $8 \mathrm{~h}$ produced little change in the XRD pattern.

The phase evolution of the MA matrix follows an entirely different course. In the green state before hot-pressing, it contained alumina (corundum), silica (a mixture of cristobalite and quartz), and a small amount of lithium silicate $\left(\mathrm{Li}_{2} \mathrm{Si}_{2} \mathrm{O}_{5}\right){ }^{8}$ After hot-pressing, the crystalline phases detected by XRD were alumina and cristobalite. Subsequently, when subject to annealing at $>1400^{\circ} \mathrm{C}$, cristobalite and alumina reacted to form mullite. This change is shown in Fig. 2, where XRD patterns of the whisker-reinforced MA, before and after annealing, are compared. We note that the final phase assemblage of the annealed MA composition was determined to be $72.7 \mathrm{wt} \%$ mullite and $27.3 \mathrm{wt} \%$ alumina, by referring to standards prepared from alumina-mullite mixtures. Also note that in all of the XRD patterns presented, the $\mathrm{SiC}$ reffections $(\beta-\mathrm{SiC})$ remain unchanged, indicating $\mathrm{SiC}$ whiskers are stable under the processing conditions. Thus, a highly refractory crystalline

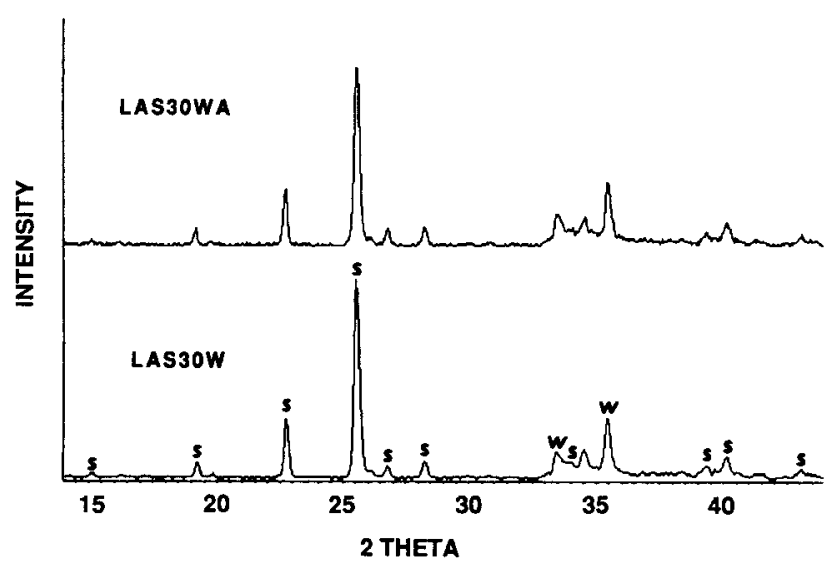

Fig. 1. XRD patterns of LAS30W and LAS30WA whisker composites. Letters $s$ and $w$ indicate spodumene and $\beta-S i C$, respectively.

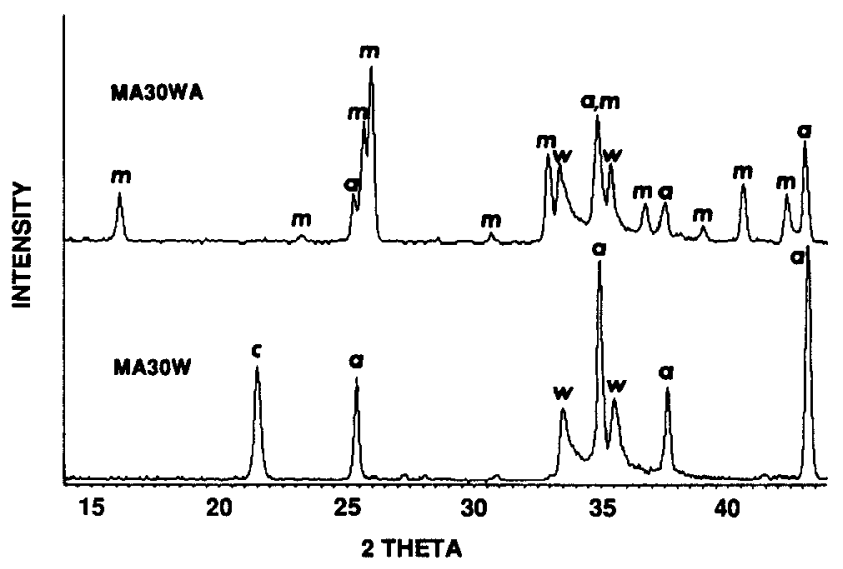

Fig. 2. XRD patterns of MA30W and MA30WA whisker composites. Letters a, c, $m$, and $w$ indicate alumina, cristobalite, mullite, and $\beta-\mathrm{SiC}$, respectively.

ceramic matrix of mullite/alumina can be obtained from the more easily processed alumina/silica glass-ceramics without affecting SiC whiskers.

The average thermal expansion coefficient values of the composites before and after annealing as measured by a dilatometer in the temperature range $20-1082^{\circ} \mathrm{C}$ are listed in Table I. For comparison, the values for alumina, ${ }^{12}$ mullite, ${ }^{13}$ and $\mathrm{SiC}^{14}$ are also included.

\section{(2) Mechanical Properties}

The fracture toughness and hardness values for LAS-III and $\mathrm{MA}$, and their SiC-whisker-reinforced composites, are listed in Table II. The hardness of MA is much higher than that of LAS-III so that only a relatively small percentage increase in the hardness of the MA composites is realized with the SiC reinforcement. Interestingly, a noticeable decrease in the hardness of both MA and its SiC composite was noted after annealing. On the other hand, the increases in fracture toughness caused by the $\mathrm{SiC}$ addition are significant for all materials, with a typical improvement around $2 \mathrm{MPa} \cdot \mathrm{m}^{1 / 2}$. The toughness of the LAS matrix composite is comparable to that (2.1-4.5 $\mathrm{MPa} \cdot \mathrm{m}^{1 / 2}$ ) found in SiC-whisker-reinforced glass and glassceramic composites. ${ }^{4}$ The toughness of the MA composite is lower than that reported $\left(5.6-9.5 \mathrm{MPa} \cdot \mathrm{m}^{1 / 2}\right)$ for $\mathrm{SiC}$-whiskerreinforced alumina ${ }^{12,15,16}$ but is similar to that $(2.8-4.6$ $\mathrm{MPa} \cdot \mathrm{m}^{1 / 2}$ ) reported for $\mathrm{SiC}$-whisker-reinforced mullite composites. ${ }^{16.17}$ This seems reasonable because the matrix of the MA composite is alumina/silica before annealing (MA30W) and mullite/alumina (MA30WA) after annealing.

Table 1. Thermal Expansion Coefficients

\begin{tabular}{lc}
\hline Material & $\begin{array}{c}\text { Thermal expansion } \\
\text { coefficient }\left(\times 10^{\circ} /{ }^{\circ} \mathrm{C}\right)\end{array}$ \\
\hline LAS30W & 4.1 \\
LAS30WA & 4.0 \\
MA30W & 7.6 \\
MA30WA & 6.2 \\
Alumina & 8.8 \\
Mullite & 5.6 \\
$\beta-S i C$ & 4.5 \\
\hline
\end{tabular}

Table II. Hardness and Toughness Values of LAS-III, MA, and Their Composites

\begin{tabular}{lcc}
\hline \multicolumn{1}{c}{ Material } & Hardness $(\mathrm{GPa})$ & Toughness $\left(\mathrm{MPa} \cdot \mathrm{m}^{1 / 2}\right)$ \\
\hline LAS-III as-hot-pressed & 7.1 & 1.1 \\
LAS-III annealed & 7.1 & 1.2 \\
LAS30W & 9.5 & 3.0 \\
LAS30WA & 9.6 & 2.9 \\
MA as-hot-pressed & 12.4 & 2.5 \\
MA annealed & 11.7 & 1.9 \\
MA30W & 14.6 & 3.7 \\
MA30WA & 13.2 & 3.8 \\
\hline
\end{tabular}


The flexural strengths of LAS-III and its composite are plotted as a function of temperature in Fig. 3. The strength of the unreinforced LAS-III is low, only slightly above $100 \mathrm{MPa}$. It remains at this level until $1000^{\circ} \mathrm{C}$, where it begins to fall rapidly at higher temperatures. Semibrittle behavior during fracture was observed for the unreinforced LAS at temperatures above $1000^{\circ} \mathrm{C}$, at which point the glass softens, as evidenced by the slight deviation from linearity of the load-bending deflection curve. The introduction of 30 vol\% SiC whisker greatly enhances the mechanical strength of the LAS. The room-temperature flexural strength has doubled. Furthermore, the strength becomes higher at intermediate temperatures, reaching $-400 \mathrm{MPa}$ at $1000^{\circ} \mathrm{C}$, above which it decreases rapidly. Such a peak in strength at an intermediate temperature has also been observed in SiC-fiber-reinforced glass and glass-ceramic composites. ${ }^{1-3.5}$ Semibrittle behavior was also observed above $1100^{\circ} \mathrm{C}$. No significant difference in the strength behavior was observed between the as-hot-pressed and annealed samples, with or without $\mathrm{SiC}$. This is not surprising, in view of the similar phase assemblage, as shown by XRD in the two sets of materials.

The flexural strength for MA and its composite are plotted as a function of temperature in Fig. 4. The room-temperature strengths of both as-hot-pressed and annealed MA samples are similar and about 3 times that of the LAS. An increase in strength with temperatures, peaking at $500 \mathrm{MPa}$ at $1000^{\circ} \mathrm{C}$, is evident in the as-hot-pressed MA; above that the strength falls rapidly. In contrast, the strength of the annealed MA is nearly temperature independent up to $1000^{\circ} \mathrm{C}$. It then decreases gradually but still maintains a strength of $200 \mathrm{MPa}$ at $1300^{\circ} \mathrm{C}$, which is comparable to the strength of LAS30W at room temperature. The SiC whisker reinforcement further enhances the strength of MA. At room temperature, the as-hot-pressed MA30W has a strength of about $800 \mathrm{MPa}$. This strength decreases monotonically with temperature, reaching $550 \mathrm{MPa}$ at $1200^{\circ} \mathrm{C}$ and 100 $\mathrm{MPa}$ at $1400^{\circ} \mathrm{C}$. For the annealed material (MA30WA), the room-temperature strength of $\sim 600 \mathrm{MPa}$ is twice as high as that of LAS30W/LAS30WA but lower than that of the as-hotpressed material. This strength is maintained at least until $1000^{\circ} \mathrm{C}$ and, more significantly, a rather high strength around $300 \mathrm{MPa}$ is still obtained at $1400^{\circ} \mathrm{C}$. Fracture of the as-hotpressed MA and MA30W manifests some semibrittle features at temperatures above $1200^{\circ} \mathrm{C}$, but is essentially brittle in the annealed MA and MA30WA until $1400^{\circ} \mathrm{C}$.

\section{(3) Microstructure and Fracture Paths}

Typical microstructures of the composites are revealed in Fig. 5, which consists of fractographs of four composites. SiC appears as elongated whiskers in these micrographs. In the ashot-pressed state, the grain size of the LAS-III matrix (1-2 $\mu \mathrm{m}$ as in Fig. 5(A)) is much coarser than that in the MA matrix $(0.3-0.6 \mu \mathrm{m}$ as in Fig. 5(B)). This difference in grain size may

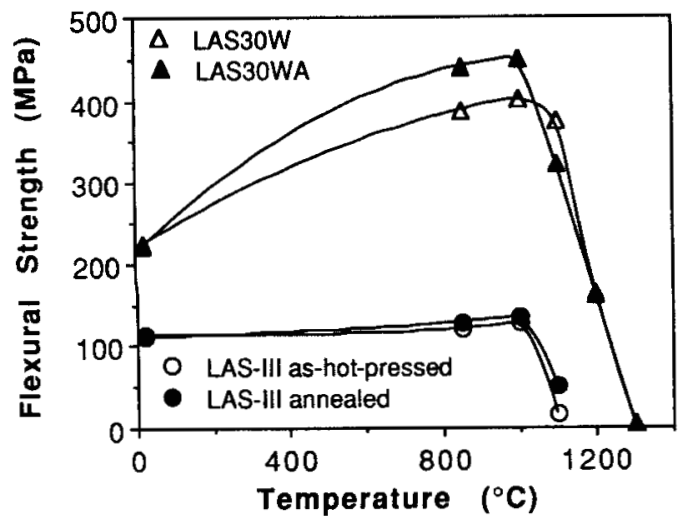

Fig. 3. Flexural strength vs temperature for LAS-III and its composites.

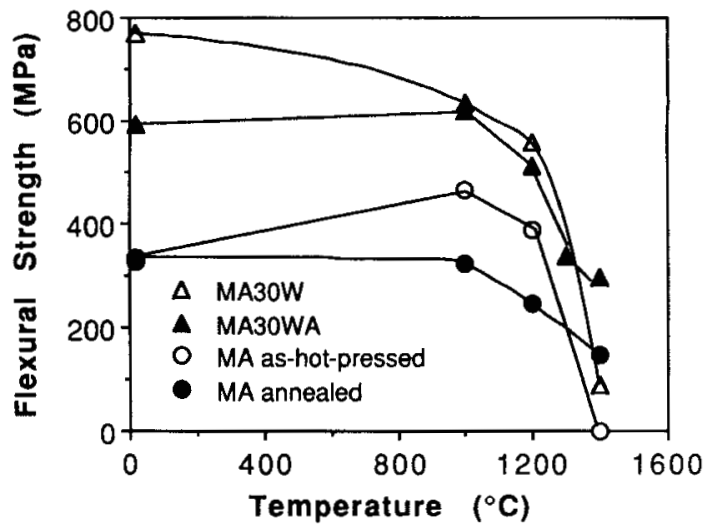

Fig. 4. Flexural strength vs temperature for MA and its composites.

be attributed to the difference in the particle sizes of the starting powders. After annealing, the grain size of the LAS matrix remains almost unchanged (Fig. $5(\mathrm{C})$ ) while that of the MA matrix coarsens to some extent $(\sim 1 \mu \mathrm{m}$ as in Fig. 5(D)). For the LAS-III composites, the fracture modes in both as-hotpressed and annealed samples are similar, as expected from their similar phase assemblages, being a mixture of intragranular and intergranular ones. For the MA composite, intergranular fracture clearly dominates in the as-hot-pressed samples where the matrix contains alumina, cristobalite, and glass. In the annealed composite, this changes into an intragranular mode which is characteristic of fracture commonly observed in alumina and mullite. Whisker debonding or pull-out, while not extensive, can be found in all cases.

Representative SEM micrographs of polished surfaces of both the LAS and MA composites are shown in Fig. 6. The polished surfaces are perpendicular to the hot-pressing axis. Whisker agglomeration is evident in both materials as expected at the 30 vol\% loading. The strong contrast between the matrix and whisker in the LAS composite is due to the presence of a heavy metal ion niobium $(\sim 5 \%)$ in the matrix. Whisker debonding, crack bridging, and crack deflection can be observed in all materials.

\section{Discussion}

\section{(1) Transient-Phase Processing}

The concept of using transient-phase processing to obtain a processable and creep-resistant matrix material for the $\mathrm{SiC}$ whisker composite is found feasible. The resultant composite is stiffer, harder, and tougher than the conventional LAS/SiC composite at all temperatures, and the advantage is most evident and important above $1000^{\circ} \mathrm{C}$. Although the scope of the present work is limited to $\mathrm{SiC}$ whisker reinforcement, we believe the same concept can be successfully extended to continuous fiber reinforcement using coated fibers of mainly $\mathrm{SiC}$ phase assemblage. ${ }^{1-3}$ (The relative thermal expansion coefficient and chemical compatibility are important, hence, the choice of $\mathrm{SiC}$.) At room temperature, further improvement would be expected in the tensile deformation behavior in the fiber direction where fiber reinforcement will result in a more "graceful" fracture behavior. At elevated temperatures, the advantage of the more refractory mullite/alumina matrix should still be realized.

Although the concept of transient-phase processing rests primarily on the slow crystallization kinetics of mullite from $\mathrm{SiO}_{2}$ and $\mathrm{Al}_{2} \mathrm{O}_{3}$, the addition of lithia proves important in practice. As we described in more detail elsewhere ${ }^{8}$ the unmodified $\mathrm{SiO}_{2}$ has a very high flow stress, even at $1350^{\circ} \mathrm{C}$, and thus is not suitable for processing composites. Lithia can modify the $\mathrm{SiO}_{2}$ network to lower its viscosity, which, at the same time, also 


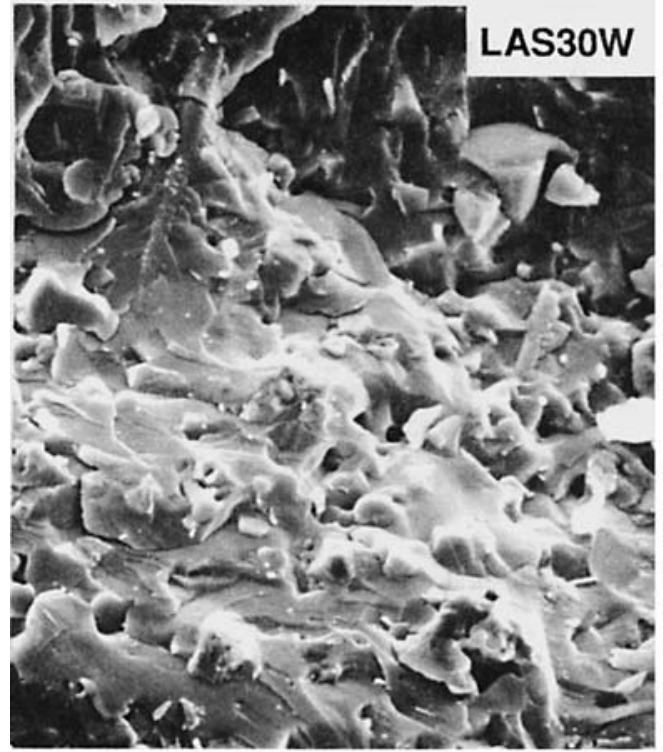

(A)

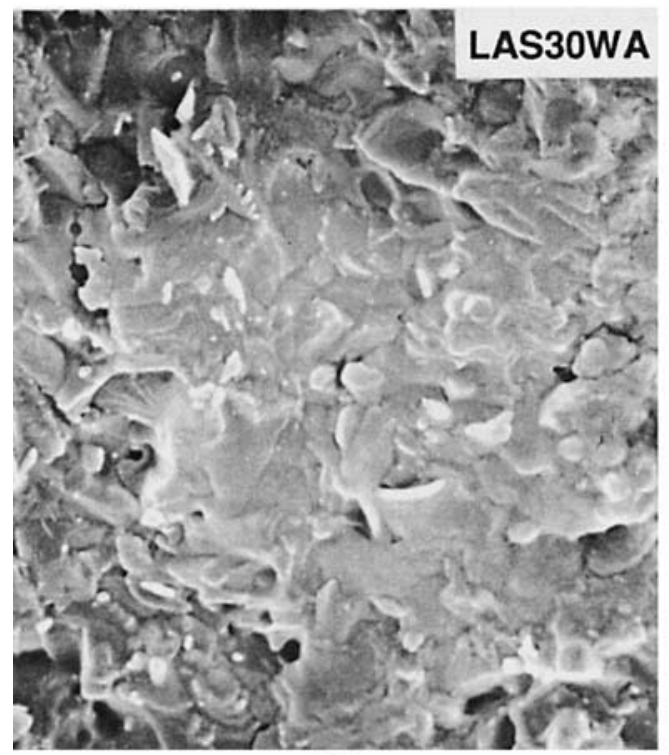

(C)

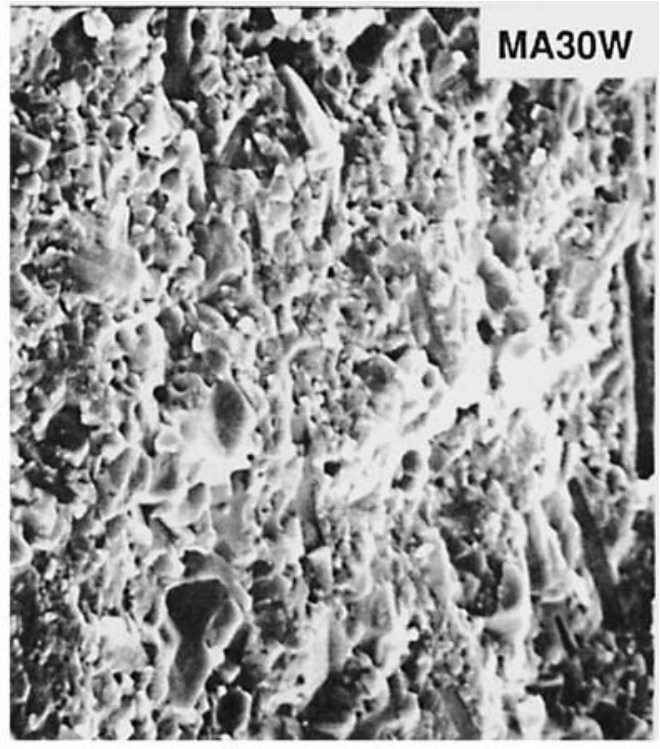

(B)

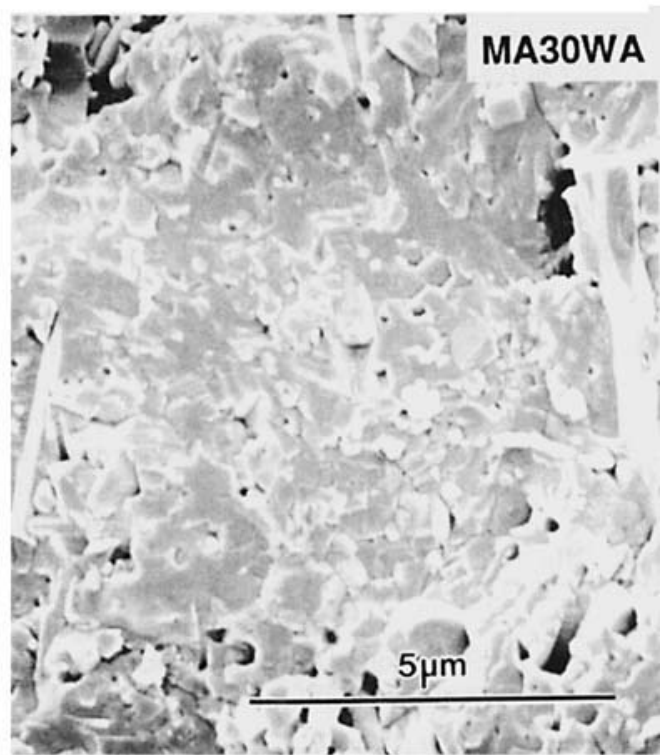

(D)

Fig. 5. SEM fractographs of LAS30W (A), MA30W (B), LAS30WA (C), and MA30WA (D).

facilitates crystallization of mullite. A processing window nevertheless has been found within which densification is sufficiently fast and mullitization is essentially absent. The present work was performed with the above knowledge on lithia composition and processing conditions in mind.

It is noted that the mullite/alumina matrix itself is not particularly tough. This is evident from the data presented in Table II. This limitation is an inherent one because mullite is not one of the tougher ceramics. For this reason, there has not been much motivation for using either mullite or mullite/alumina as the matrix for whisker-reinforced composites. Instead, alumina/SiC whisker composites are known to deliver much better toughness. ${ }^{12,15,16}$ Such composites, however, typically require a very high hot-pressing temperature, in excess of $1600^{\circ} \mathrm{C}$, compared to $1375^{\circ} \mathrm{C}$ in the present case using the transient-phase processing method. Since continuous SiC-type fibers usually have poorer stability than single-crystalline $\mathrm{SiC}$ whiskers at higher temperatures, it is probably not feasible to use an alumina matrix in the case of continuous fiber composites.

Lastly, the very nature of slow kinetics of mullitization implies that a certain amount of residual glassy phase will still remain even after annealing. This phase is the ultimate factor limiting the high-temperature strength of the mullite-type matrix. It may also affect the load transfer between reinforcement and the matrix, and the magnitude of thermal stresses in the composite. Presumably, further means for optimization of the composite properties can be suggested through a better characterization and understanding of these aspects.

\section{(2) Role of Thermal Stresses in MA Composites}

One factor that affects thermal-mechanical behavior of the LAS/SiC composites and the MA/SiC composites is the coefficient of thermal expansion (CTE). In the order of decreasing coefficient, the various phases and composites can be ranked as

$$
\begin{aligned}
& \text { alumina }>\mathrm{MA}>\mathrm{MA}(\text { annealed })>\text { mullite }> \\
& \mathrm{SiC}>\mathrm{LAS} \sim \mathrm{LAS}(\text { annealed })
\end{aligned}
$$

The above sequence should be obvious by inspection of the data in Table I. This, along with the different softening temperature of the two matrices, is used in the following to rationalize some observations on the mechanical properties. 

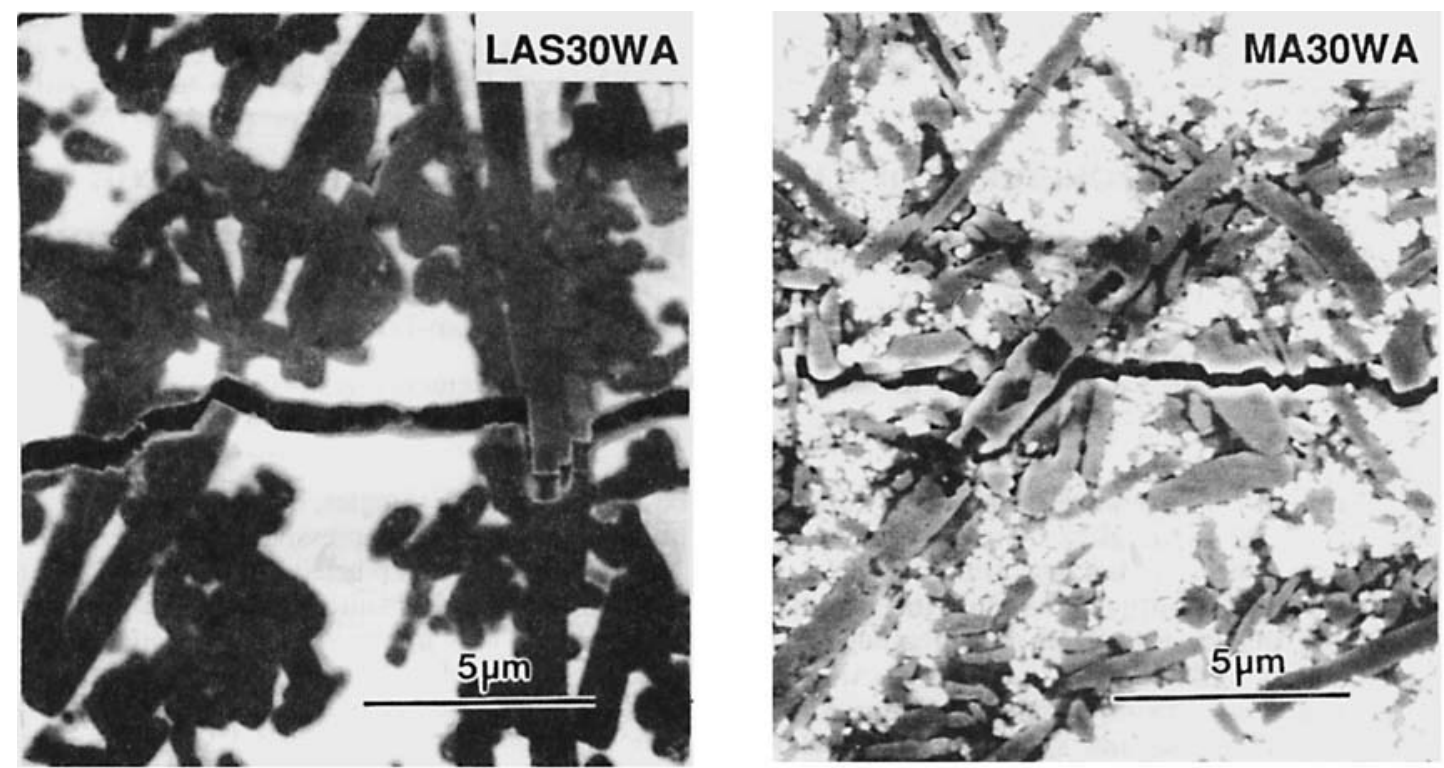

Fig. 6. SEM micrographs of polished surfaces LAS30WA and MA30WA. The indentation crack path is also shown.

First, we note that the MA matrices have higher CTE than $\mathrm{SiC}$. Hence, they are expected to be in tension when cooled to room temperature. The magnitude of the residual stress, however, is dependent on the difference between the softening temperature and room temperature. Since annealing is expected to remove most of the glass phase in the MA matrix, leaving essentially mullite and alumina, the softening temperature and hence tensile residual stress in the MA30WA composite are probably higher than those in the MA30W composite. If so, then the difference in the flexural strength of MA30W and MA30WA at room temperature might be partly attributed to the difference in the matrix residual tensile stress in these materials. Along the same line of reasoning, we may expect some microcrack formation in the annealed MA and MA30WA, which have a lower hardness than their unannealed counterparts. Similar strength degradation after annealing has also been reported for glass-containing silicon nitride/ $\mathrm{SiC}$ whisker composites in which crystallization has occurred. ${ }^{18}$ In this case, mismatch due to volume change during crystallization was suggested to cause microcracking, which is also likely to take place during crystallization of the present sets of MA composites.

\section{Conclusions}

(1) Through the use of a transient-phase processing method, a SiC-whisker-reinforced composite with a matrix (MA) composed of alumina, cristobalite, and a pre-mullite glass has been obtained. The composite can be heat-treated at $1450^{\circ} \mathrm{C}$ to convert the matrix to a mullite/alumina mixture.

(2) The MA composite has superior mechanical properties over the LAS composite. It is stiffer, harder, and tougher at all temperatures. It maintains a relatively high flexural strength of $\sim 300 \mathrm{MPa}$ at $1400^{\circ} \mathrm{C}$ which cannot be obtained in the comparable LAS composite above $1100^{\circ} \mathrm{C}$. The coefficient of thermal expansion, however, is higher in the MA composite than in the LAS composite.

(3) The MA composition, when aided with the transientphase processing method, may be chosen as a candidate matrix for composites. Its combination with the Nicalon fibers is especially recommended.

(4) Based on the considerations of thermal expansion coefficients and softening points in the MA- and LAS-based composites, significant effects of residual thermal stress, microcracking, and residual glassy phase on strength behavior are suggested.

Acknowledgment: We are grateful to Dr. Kenneth Chyung of Corning Glass Works for helpful discussions on the composition and processing conditions of LAS-III and for supplying the LAS-III powder.

\section{References}

'K. M. Prewo and J. J. Brennan, "High Strength Silicon Carbide Fiber Reinforced Glass-Matrix Composites," J. Mater. Sci., 15, 463-68 (1980).

'K. M. Prewo and J. J. Brennan, "Silicon Carbide Yarn Reinforced Glass Matrix Composites,"J. Mater. Sci., 17, 1201-206 (1982).

J. J. Brennan and K. M. Prewo, "Silicon Carbide Reinforced Glass-Ceramic Matrix Composites Exhibiting High Strength and Toughness," J. Mater. Sci., 17, 2371-83(1982)

${ }^{4} \mathrm{~K}$. P. Gadkaree and K. Chyung, "Silicon-Carbide-Whisker-Reinforced Glass and Glass-Ceramic Composites, "Am. Ceram. Soc. Bull . 65 [2] 370-76 (1986).

${ }^{5}$ K. M. Prewo, "Tension and Flexural Strength of Silicon Carbide Fiber-Reinforced Glass Ceramics," J. Mater. Sci., 21, 3590-600 (1986).

"T. Mah, N. L. Hecht, D. E. McCullum, J. R. Hoenigman, H. M. Kim, A. P. Katz, and H. A. Lipsitt, "Thermal Stability of SiC Fibers (Nicalon)," J. Mater. Sci, $19[4]$ i 191-201 (1984)

${ }^{7}$ S. M. Johnson, R. D. Brittain, R. H. Lamoreaux, and D. J. Rowcliffe, "Degradation Mechanisms of Silicon Carbide Fibers," J. Am. Ceram. Soc., 71 [3] C-132-C-135 (1988).

${ }^{x} \mathrm{~L}$. A. Xue and I-W. Chen, "Fabrication of Mullite Body Using Superplastic Transient Phase," J. Am. Ceram. Soc., 75 [5] 1185-91 (1992).

'L. A. Xue and I-W. Chen; unpublished work.

${ }^{11} G$. R. Anstis, P. Chantikul, B. R. Lawn, and D. B. Marshall, "A Critical Evaluation of Indentation Techniques for Mcasuring Fracture Toughness: I, Direct Crack Measurements,"J. Am. Ceram. Soc., 64 [9] 533-38 (1981).

"Powder Diffraction File, Card Nos. 35-797 and 39-49. Joint Committee on Powder Diffraction Standards, Swarthmore, PA.

${ }^{2}$ J. Homeny, W. L. Vaughn, and M. K. Ferber, "Processing and Mechanical Properties of SiC-Whisker- $\mathrm{Al}_{2} \mathrm{O}_{3}$-Matrix Composites," Am. Ceram. Soc. Bull. 67 [2] 333-38 (1987).

"K. S. Mazdiyasni and L. W. Brown, "Synthesis and Mechanical Properties of Stoichiometric Aluminum Silicate (Mullite),"J. Am. Ceram. Soc., 55 [11] 548-52 (1972).

${ }^{14} \mathrm{Z}$. Li and R. C. Bradt, "Thermal Expansion and Thermal Expansion Anisotropy of SiC Polytypes," J. Am. Ceram. Soc., 70 [7] 445-48 (1987)

P. F. Becher and G. C. Wei, "Toughening Behavior in SiC-Whisker-Reinforced Alumina," J. Am. Ceram. Soc., 67 [12] C-267-C-269 (1984)

${ }^{10} \mathrm{G}$. C . Wei and P. F. Becher, "Development of SiC-Whisker-Reinforced Ceramics," Am. Ceram. Soc. Bull, 64 [2] 298-304 (1985)

${ }^{17}$ T. Kumazawa, S. Ohta, H. Tabata, and S. Kanzaki. "Mechanical Properties of Mullite-SiC Whisker Composites," J. Jpn. Ceram. Soc., 97 [9] 895-902 (1989).

${ }^{\text {'x }} \mathrm{S}$. D. Nunn, "Processing and Properties of $\mathrm{SiC}$ Whisker Reinforced $\mathrm{Si}_{3} \mathrm{~N}_{4}$ Composites"; Ph.D. Dissertation. Department of Materials Science and Engineering, University of Michigan, Ann Arbor, MI, 1991

"A. G. Evans and D. B. Marshall, "The Mechanical Behavior of Ceramic Matrix Composites," Acta Metall., 37 [10] 2567-83 (1989). 